\title{
SEXUALIDADE E ESCOLA: UMA DISCUSSÃO NECESSÁRIA
}

\author{
Jessica Sampaio FIORINI ${ }^{1}$ \\ Gilsenir Maria Prevelato de Almeida DÁTILO ${ }^{2}$
}

RESUMO: O presente artigo parte de uma problematização acerca do tema da sexualidade, bem como da forma como esta é concebida especificamente pela escola. Assim, busca-se explicitar e discutir algumas concepções e conceitos difundidos no decorrer da história sobre a sexualidade humana, e sobre a institucionalização do ensino acerca do assunto, sendo essa oficializada, no Brasil, por meio dos Parâmetros Curriculares Nacionais (PCNs) (BRASIL, 1998). Para tanto, são expostas ideias e conceitos de diferentes autores/as que tratam do tema, na tentativa de proporcionar aos/às leitores/as a reflexão sobre a forma como a sexualidade vem sendo concebida pelas instituições sociais, em especial, pela escola e sobre as dificuldades encontradas ao trabalhar-se com a temática no âmbito escolar. Tendo como pressuposto que a sexualidade é inerente à vida e considerando o fato de que as concepções do indivíduo a respeito da mesma se fazem ao longo de sua vivência, é de extrema importância a realização de estudos que dizem respeito a como esta questão se dá no espaço escolar. Dessa forma, espera-se que este artigo possa contribuir com os demais estudos e pesquisas realizadas sobre o tema em questão.

PALAVRAS-CHAVE: Escola. Sexualidade. Educação sexual. Orientação sexual. Parâmetros Curriculares Nacionais.

\section{Introdução}

O atual conceito de sexualidade, difundido por diversos estudiosos contemporâneos, trouxe uma nova concepção acerca do assunto, atribuindo-lhe um sentido para além da questão da relação sexual e passando a abranger várias outras dimensões que envolvem também a subjetividade do ser humano. Entretanto, esse amplo olhar sobre a sexualidade humana, nem sempre fez parte da realidade das instituições sociais, sendo o tema muitas vezes transformado em um tabu.

Segundo Ribeiro (2002) e Souza (1997), a concepção da sociedade sobre a sexualidade, identificada na história, sempre sofreu influências de instituições, correntes

${ }^{1}$ Graduação em Pedagogia. Faculdade de Filosofia e Ciências. UNESP - Universidade Estadual Paulista Júlio de Mesquita Filho. Professora da Prefeitura Municipal de Marília. Mestranda do Programa de Pós Graduação em Educação. UNESP - Universidade Estadual Paulista Júlio de Mesquita Filho. Marília - SP - Brasil. 17525-901 - jessicafiorini.unesp@gmail.com.

${ }^{2}$ Doutorado em Educação. UNESP - Universidade Estadual Paulista Júlio de Mesquita Filho. Professora Assistente Doutora. UNESP - Universidade Estadual Paulista Júlio de Mesquita Filho, Departamento de Psicologia da Educação. Marília - SP - Brasil. 17525-901 - gdatilo@gmail.com. 
ou grupos que tinham o domínio do discurso em cada época, de forma que um discurso não eliminasse o outro.

Assim, conforme Ribeiro (2002), até o século XVIII, a Igreja tinha domínio sobre o discurso a respeito da sexualidade e dos comportamentos sexuais, onde havia certa preocupação com a moral, relacionando-o com o sentimento de pecado. Segundo Braga (2003, p.154):

[...] para a Igreja o sexo deveria ser praticado unicamente como uma finalidade reprodutiva. Toda a busca do prazer seria condenável mesmo entre os cônjuges. A copulação deveria servir só para dar a luz. Dessa forma, a monogamia e a virgindade para as mulheres passam a ser valorizadas como símbolos de virtude.

Ou seja, os comportamentos sexuais deveriam ser evitados e a sexualidade era relacionada apenas à dimensão reprodutiva, sendo pecaminosos aqueles que, de alguma forma, não seguissem as condutas religiosas.

Segundo Souza (1997), nessa época, a sexualidade se mostrava alheia ao interesse do indivíduo e estranha à sua vontade. Tendo sua função limitada à reprodução da espécie, ignorava-se as relações humanas envolvidas na questão da sexualidade, sendo considerada anomalia a ausência do instinto ou a presença de sua manifestação que não tivessem o fim de procriação.

Se a sexualidade tivesse por objetivo a reprodução, seria normal sua manifestação enquanto o aparelho reprodutivo estivesse funcionando. Logo, ela deveria se manifestar apenas na puberdade e durar até o término da atividade reprodutiva. Logicamente, seriam anormais a sexualidade infantil e a manifestação da sexualidade na velhice. (SOUZA, 1997, p.15).

Dessa forma, a sexualidade estaria restrita apenas a um determinado período da vida do ser humano, quando este está apto a reproduzir-se. Ignora-se assim, a manifestação da sexualidade na infância e na velhice, sendo compreendida de forma a limitá-la à reprodução da espécie, ao sexo entre cônjuges heterossexuais que objetivassem ter filhos ou filhas.

Na Europa, a partir do século XIX, no entanto, após o desenvolvimento das ciências biológicas, o discurso médico, com ideais higienistas, passou a ter grande prestígio em relação às condutas sexuais, sendo orientadores da sociedade em relação aos comportamentos ligados à sexualidade (RIBEIRO, 2002). 
Dessa forma, “[...] o discurso médico substituiu o discurso religioso, e a 'ciência' passou a dar explicações que antes apenas tinham a conotação moral e o sentido de pecado dados pela religião católica.” (RIBEIRO, 2002, p.11). No entanto, isso não significou que a doutrina da Igreja referente à conduta sexual tivesse se extinguido, pois a moral proferida pela religião, ainda estava presente nas questões relacionadas ao sexo.

Assim, a medicina passou a ter argumentos críticos sobre a educação e às condutas de professores, defendendo posturas que estivessem em consonância com as ideias de proteção à saúde infantil, com a preocupação voltada às perversões sexuais (RIBEIRO, 2002).

De acordo com o autor, o discurso referente à sexualidade no Brasil, acompanhou o proferido na Europa, com influências de estudos da área médica, e das doutrinas advindas da Igreja Católica. Em realidade, porém:

[...] o povo tinha conduta própria cujas atitudes e comportamentos visavam atender às necessidades sexuais de uma população carente de mulheres brancas, num período inicial, e, depois, possuidora de um grande número de mulheres escravas que eram obrigadas a satisfazer $o$ desejo sexual dos senhores brancos. (RIBEIRO, 2002, p.12).

Sendo assim, parece que o discurso trazido da realidade européia, embora alcançasse o Brasil, não ocorria em prática, ficando apenas mesmo no discurso. $\mathrm{O}$ objetivo do sexo aqui, não seria o da reprodução da espécie, mas sim, o prazer carnal dos senhores brancos, aliado à subjugação das mulheres negras, as quais seriam incumbidas da responsabilidade de proporcionar tal prazer, oferecendo-lhes seus próprios corpos para tanto.

As posturas antissexuais, ainda presentes nos tempos atuais, se originaram, sobretudo, no século XIX, quando as fortes atitudes antissexuais da época, se propagaram por todo o mundo ocidental e no Brasil, as ideias difundidas pela medicina, com cunho higienista, persistiram até a metade do século XX (RIBEIRO, 2002).

Assim, concepções antissexuais persistiram por longo tempo, instaurando-se uma postura repressora, que propagava uma compreensão limitada a respeito do tema, pois, enquanto a moralidade advinda do discurso da Igreja trazia uma compreensão na qual a sexualidade estaria relacionada ao sexo e que este, por sua vez, seria restrito a cônjuges e à reprodução sexual, sendo transmitida também a ideia de pecado, a corrente 
médico-higienista, por sua vez, estaria mais preocupada com a prevenção de doenças venéreas.

Pesquisas foram sendo realizadas, e a compreensão sobre a sexualidade foi se ampliando, sendo concebida para além da dimensão reprodutiva, onde estaria relacionada apenas ao sexo em si, quando na verdade, abarca questões subjetivas, envolvendo o gênero, os sentimentos, o desejo, a busca pelo prazer, entre outros aspectos, além de ser um tema que pode ser concebido por diferentes olhares, pois abrange questões filosóficas, psicológicas, sociais e históricas, conforme a definição estabelecida por Ribeiro (2005) e pela OMS (1975 apud SILVA, 2002).

Segundo Ribeiro (2002), a década de 1980 foi marcada pela ocorrência de movimentos liberais, influenciando nas condutas sexuais da época, quando a questão do sexo passou a se aliar à liberdade. Surgiu então a preocupação de pais e educadores com a possibilidade de ocorrência de gravidez indesejada, e a contração de doenças sexualmente transmissíveis pelos seus filhos e filhas. Nesse sentido, foi sendo identificada a necessidade de se abordar o tema sexualidade nas escolas. Muitas foram as reivindicações a respeito da introdução do ensino sistematizado sobre sexualidade no espaço escolar, como também a resistência de instâncias superiores, influenciadas ainda por concepções limitadas sobre o tema, como assinalam Sayão (1997), Werebe (1998) e Guimarães (1995).

Além disso, Ribeiro (1990) assevera que a sexualidade passou a ser tratada de maneira superficial pela mídia, não havendo a preocupação com certos valores universais e sendo aliada ao mercado capitalista presente nas propagandas.

Foi então que na década de 1990, após tempos de lutas, a sexualidade foi introduzida oficialmente no currículo educacional brasileiro, por meio dos Parâmetros Curriculares Nacionais (PCNs) ${ }^{3}$ (BRASIL, 1998), sendo proposta como um tema transversal para ser trabalhado em projetos de "Orientação Sexual”.

Assim, pode-se dizer que a necessidade de se abordar a sexualidade na escola vem sendo reconhecida pela sociedade e, conforme visto, passou a ser uma questão de política pública, sendo transposta por meio de um documento orientador das práticas educacionais, os PCNs (BRASIL, 1998). Considera-se, pois, importante a discussão acerca das possibilidades e dificuldades da escola em abordar o tema sexualidade, assim

${ }^{3}$ Os Parâmetros Curriculares Nacionais (BRASIL, 1998) constitui-se em um documento da Secretaria de Educação Fundamental, Ministério da Educação, sendo um instrumento norteador das práticas docentes para o terceiro e quarto ciclos do ensino fundamental. 
como é proposto nos PCNs, o que demandaria o esclarecimento de algumas questões, tais como: De que maneira a sexualidade vem sendo concebida atualmente? A sociedade fala sobre sexualidade? De que forma? E a escola, como vem trabalhando o tema com os educandos? Quais as principais dificuldades encontradas pela escola ao se abordar o tema? Quais os caminhos possíveis?

Conforme visto, a sexualidade nos últimos tempos passou a ser compreendida por estudiosos/as e pesquisadores/as de forma ampla. No entanto, em prática, não deixou de ser abordada de maneira limitada pelas instituições sociais e pelos meios de comunicação. De acordo com Ribeiro (1990), se por um lado os valores morais transmitidos pela família transformam a sexualidade do/a jovem em um tabu, por outro, os meios de comunicação, mais especificamente a televisão, passam ideias superficiais sobre as questões sexuais. Sobre este assunto Gagliotto e Lembeck (2011, p.101) afirmam:

\begin{abstract}
A mídia estabelece os padrões e impulsiona o consumismo, utilizando-se de apelos à sexualidade. Mulheres e homens belos usam do poder da sedução na televisão, que age como uma "medusa" frente aos seus admiradores, os quais, petrificados e hipnotizados, acreditam no falso erotismo, quando o que ocorre na verdade é a banalização do sexo e o princípio da deserotização.
\end{abstract}

Dessa forma, a mídia transmite à sociedade que a acompanha, certos padrões e conceitos relacionados à sexualidade que, em realidade, são superficiais, sendo utilizados em benefício do comércio. Conforme Ribeiro (1990), os meios de comunicação interferem nas mudanças de comportamento da sociedade, especialmente a televisão, em razão de um número maior de pessoas que consegue ter acesso a ela.

Podemos observar propagandas onde são vistos corpos de jovens, em sua maioria mulheres, aliados aos produtos consumíveis, músicas que são disseminadas em rádios ou em programas de televisão que retratam o sexo de maneira superficial e, muitas vezes, desrespeitosa para com as mulheres, além de telenovelas que transmitem certas condutas relacionadas à sexualidade.

Para Ribeiro (1990) implicitamente essas propagandas, como também os programas televisivos e as novelas, conduzem opiniões e condutas em relação à sexualidade. De acordo com ele, revelam uma despreocupação com valores universais, tal como o respeito ao outro, pois a ideia transmitida faz alusão a uma sexualidade tratada de maneira superficial e materializada, desconsiderando-se questões que fazem 
parte do tema, tais como a afetividade, os sentimentos e as sensações, construídos por meio das relações humanas.

A família, por sua vez, embora seja considerada a instituição primeira responsável pela educação, conforme Santos e Bruns (2000), ainda encontra dificuldades em lidar com os assuntos relacionados à sexualidade:

Esse descompasso entre pais e filhos está centrado na ausência de diálogo sobre os assuntos ligados ao sexo, omissão, respostas incompletas ou erradas, censuras, dificuldades de comunicação, ignorância, pouca disponibilidade de tempo, dentre outros fatores. (SANTOS; BRUNS, 2000, p.21).

Ideias, valores e concepções sobre a sexualidade são transmitidos pela família de forma insatisfatória para o esclarecimento das crianças e jovens. Ainda que não haja um diálogo entre pais e filhos/as sobre o assunto, é transmitida uma mensagem que influencia na compreensão sobre o tema, transformando-o em um tabu ou em um assunto que não deve ser comentado, ou seja, a concepção sobre a sexualidade adquirida torna-se limitada, visto que essa não é abordada como algo inerente à vida.

Além disso, "[...] essa falta de escuta por parte dos pais, no que se refere aos desejos e aos questionamentos dos adolescentes, reflete diretamente nos seus comportamentos sexuais, tais como gravidez precoce, doenças sexualmente transmissíveis, abortos, etc. (GAGLIOTTO; LEMBECK, 2011, p.107). As autoras querem dizer que, ao não encontrar com a própria família as explicações e informações a respeito de questões associadas à sexualidade, o adolescente acaba por compreender esta como um tabu, e depois, por razão da falta de informações e conhecimentos suficientes, opta por tomar condutas inconsequentes.

Outras vezes, conforme as autoras acima citadas, os/as jovens procuram sanar suas dúvidas e questões, por meio de fontes menos seguras, tais como sites encontrados na internet, revistas, ou até mesmo com outros/as colegas. O problema é que nem sempre esses meios transmitem informações adequadas, e se o/a jovem não puder realizar uma seleção dos conteúdos, acaba por incorporá-las de forma inadequada.

Outro assunto a ser considerado refere-se às relações de gênero. Assim como na constituição da sexualidade, como explica Kahhale (2011), a concepção do indivíduo sobre o feminino e o masculino se dá pelas influências do meio externo até mesmo antes de seu nascimento, estando presente nas relações familiares e sociais, bem como na forma como a família é constituída. 
Aliás, a respeito da família, podemos dizer que, atualmente, são reconhecidos diversos modelos que podem se configurar como tal, superando a ideia da família nuclear como sendo a única configuração que poderia ser definida enquanto família. A menção a respeito dos modelos de família torna-se importante, neste sentido, ao passo que mantém relação com a construção do gênero, pois, ao nascer, o indivíduo já começa a sofrer influências das concepções e conceitos já existentes no meio social, onde é inserido, a respeito da sexualidade, o que poderá determinar suas próprias concepções acerca dos gêneros existentes.

Essa relação entre os modelos de família e a construção do gênero é assinalada por Santos e Bruns (2000), as quais apontam que o modelo de família nuclear, embora tenha maior predominância na sociedade, é apenas mais um entre os vários outros existentes. Podemos citar neste caso, as famílias constituídas somente pela presença da mãe ou do pai que criam o/ filho/a; constituídas por avós que criam os/as netos/as; famílias onde os cônjuges são do mesmo sexo; etc., nas quais cada papel desempenhado é um importante determinante na formação das concepções acerca das relações de gênero para os indivíduos que nelas nascem.

Mulheres foram conquistando espaços na sociedade, que, em períodos anteriores, eram somente ocupados por homens. Recentemente, no Brasil, o Conselho Nacional de Justiça (CNJ) aprovou uma resolução que autoriza o casamento civil entre casais homossexuais, segundo Seligman (2013). Esses acontecimentos são apenas alguns dentre outros importantes que marcaram períodos históricos de conquistas para a história das relações de gênero.

Assim, presentemente, no século XXI, de acordo com Gagliotto e Lembeck (2011), é possível reconhecer alguns avanços quanto a esse assunto, porém, há que se perceber a existência de questões que ainda poderiam ser modificadas, mas que sofrem influências de tradições de ordem teológicas ou médicas, que são carregadas de concepções repressoras sobre a sexualidade. Muitas vezes, podemos observar casos de homofobia, por exemplo, sendo denunciados nos meios de comunicação, o que retrata ainda a ignorância e preconceito por parte de algumas pessoas, acerca das novas concepções sobre a sexualidade, as relações de gênero, bem como do reconhecimento da diversidade na sociedade.

Em relação à educação, por exemplo, Santos e Bruns (2000) apontam algumas considerações estabelecendo uma comparação entre a educação sexual das meninas e 
dos meninos, considerando que a construção do gênero é um tema intrínseco à discussão sobre a abordagem da sexualidade. Dessa forma elas afirmam:

Embora vivamos em um período de transição, no qual os papéis sexuais estejam sendo reavaliados e revistos, os filhos e filhas são educados de maneiras distintas. Em razão de tal comportamento, é possível perceber restrições às meninas e maior liberdade aos meninos, embora ambos tenham acesso às mesmas informações. (SANTOS; BRUNS, 2000, p.37).

Segundo as autoras, enquanto que para as meninas as informações a respeito da sexualidade são veladas ou insuficientes, reflexo da repressão sexual dos adultos, para os meninos a iniciação sexual é incentivada, embora não se discutam a responsabilidade que devem assumir frente a seus relacionamentos.

Recentemente, foi trazida para a discussão a questão do homossexualismo, num programa de televisão de uma emissora que atinge um grande público no Brasil. Um dos convidados para falar sobre o assunto era o então deputado federal Jean Wyllys (2013), assumido homossexual.

Wylls (2013) trouxe para a discussão sua angústia vivida na fase quando ainda estava se descobrindo homossexual, momento no qual ainda não conseguia compreender a si mesmo por não se sentir representado nos meios de comunicação, nos livros didáticos, entre outros lugares. A discussão mostrou que a dificuldade da aceitação e compreensão da sociedade sobre o homossexualismo ainda ocorre, e o que é mais surpreendente, que na própria família, ainda há essa dificuldade.

Segundo Silva (2002, p.59):

Há sempre o desejo de encontrar a verdade absoluta e única, ponto ao qual todos devem chegar, independentemente das características e dos desejos individuais. Há uma tentativa de colocar todos dentro do mesmo padrão, de esperar de todos, a mesma forma de ver o mundo e de viver. $\mathrm{E}$ isto acentua-se nas questões da sexualidade, pois estas necessariamente precisam ser 'vigiadas e punidas', caso comecem a 'extrapolar' os limites do já preestabelecido.

Essa tentativa de padronização da sociedade é o germe da não aceitação do que parece ser diferente ou fora do comum no âmbito social, o que abre caminho às atitudes preconceituosas e discriminatórias até mesmo por parte da família do indivíduo. Dessa forma, é possível compreender a necessidade de ter-se maior número de espaços em que sejam possibilitadas discussões com maior amplitude sobre temáticas como essa, para 
que, por meio do conhecimento, fosse plausível combater o preconceito e os conceitos equivocados da sociedade sobre a sexualidade, o gênero e a identidade sexual.

A escola também é um importante veículo influenciador das concepções referentes à sexualidade. Com a introdução do tema nos Parâmetros Curriculares Nacionais (BRASIL, 1998), na década de 1990, sendo um dos temas transversais contidos no documento, foi pensada a possibilidade de abordar a sexualidade de forma sistematizada no âmbito escolar, por meio da proposta destinada à "Orientação Sexual" - forma como fora definida a parte dos PCNs (BRASIL, 1998) onde são apresentadas ideias, conceitos, justificativas, objetivos, propostas, entre outros itens, para a abordagem do tema sexualidade, na escola.

São inúmeros os fatores, assinalados pelos/as diversos/as autores/as e estudiosos/as da área da educação ou de áreas afins, que justificam a necessidade de a escola falar sobre sexualidade e não continuar ignorando algo que evidentemente existe no ser humano, estando este dentro ou fora do ambiente escolar, assim como se reconhece nos PCNs (BRASIL, 1998).

Os/As alunos/as passam grande parte de seu tempo na escola, durante muitos anos de sua vida. A sexualidade é intrínseca a esse período, estando presente nas relações interpessoais, ou em algumas outras manifestações típicas dos/as educandos/as, como por exemplo, pichações de carteiras, paredes e muros, como também nas brincadeiras feitas entre eles/as (REIS; RIBEIRO, 2005; SANTOS; BRUNS, 2000; AQUINO, 1997). Essas manifestações e atitudes percebidas deixam evidente que, de alguma forma, os/as educandos/as expressam sua necessidade de falar sobre a sexualidade dentro do espaço escolar, buscando diversos meios para exporem essa necessidade.

No entanto, a escola nem sempre cumpre seu papel neste assunto, e onde deveria ser um lugar para o esclarecimento e discussão de temas como esses, acaba sendo mais um a transformá-lo em tabu. Assim, a escola opta por reprimir as manifestações da sexualidade em seu espaço, onde demonstrações de afetos entre alunos/as não são permitidas e onde a sexualidade é compreendida como um fator perturbador da ordem existente (SANTOS; BRUNS, 2000).

Por outro lado, existem algumas tentativas providenciadas por algumas escolas, por parte da equipe escolar, para a abordagem de temas referentes à sexualidade. Porém, nessas tentativas, a escola por vezes transmite concepções errôneas, onde a temática é 
assimilada a algo que apresenta perigo, conforme ocorre quando é discutida a questão do sexo.

Problemas como as doenças sexualmente transmissíveis (DST's), em especial a AIDS, além da gravidez indesejada, são destacados em detrimento de assuntos que deveriam ser abordados com maior enfoque no trabalho com a sexualidade na escola, disseminando uma ideia para os/as educandos/as de que essa é algo negativo para suas vidas (REIS; RIBEIRO, 2005).

Em outras palavras, quando as informações a respeito da temática em questão são transmitidas apenas por meio de atividades de prevenção de doenças ou outras ocorrências desencadeadas pela desinformação sobre o assunto, os/as educandos/as podem desenvolver a compreensão de que a sexualidade só poderia proporcionar problemas, quando de fato ela pode proporcionar prazer ao indivíduo desde que este tenha responsabilidade sobre ela.

Outro fator observado pelos autores refere-se à "biologização" da sexualidade. Ribeiro (1990), Santos e Bruns (2000), Silva (2002), entre outros, assinalam que nas escolas, geralmente, o tema é abordado por professores/as que atuam na área de Ciências Biológicas, os quais abordam, entre outros assuntos, a anatomia do corpo humano, bem como a função reprodutiva do sexo, o que, segundo Gagliotto e Lembeck (2011), embora sejam temas que contribuam para o conhecimento acerca da sexualidade, são insuficientes, se não forem abrangidas questões de ordem social, política, histórica, entre outras, necessárias para uma ampla compreensão sobre a sexualidade.

Nesse caso, ainda que esse conteúdo seja importante, se as questões sexuais forem transmitidas somente por meio das disciplinas de Ciências Biológicas, o/a educando/a poderá associar a sexualidade apenas à dimensão da reprodução humana e às doenças, obtendo assim, um conceito limitado a respeito do tema, ao considerarmos que ele abrange não apenas o sexo em si. Além disso, em se tratando de sexo, sabe-se que, não necessariamente, este estaria relacionado à reprodução da espécie, conforme amplamente discutido aqui.

Desse modo, Gagliotto e Lembeck (2011) afirmam que se a escola não tratar da questão sexual ou se tratar apenas por meio da dimensão biológica do assunto, estaria disseminando entre os/as alunos/as, a impressão de que se trata de um tema que é mesmo um tabu, sobre o qual não se pode falar. 
Em realidade, embora não se fale sobre as outras questões tais como o prazer e a afetividade, as quais estão envolvidas numa compreensão maior sobre a sexualidade humana, os/as educandos/as não deixam de ter sua curiosidade sobre esses assuntos, pois os vivem e sentem, ou pelo menos, os observam em seu cotidiano e mesmo através de filmes, telenovelas, como também em outros meios que transmitem histórias fictícias sobre relacionamentos amorosos.

Assim, a falta de informações mais completas na escola, faz com que as crianças e os/as adolescentes, para satisfazerem suas dúvidas e curiosidades, procurem respostas em fontes menos confiáveis como, por exemplo, em sites presentes na internet, ou com outros/as colegas (GAGLIOTTO; LEMBECK, 2011). A fala da autora deve-se ao fato de que esses meios, possivelmente, não teriam informações suficientes, nem o conhecimento adequado para a situação e, conforme já mencionado anteriormente, poderiam trazer também informações e conceitos equivocados a respeito da sexualidade, bem como das questões nela envolvidas, exceto se fossem utilizados por indivíduos que já têm certo conhecimento sobre o assunto pesquisado.

Essa busca por uma compreensão sobre a sexualidade por outros meios que não a escola e a família, de acordo com Braga (2003), deve-se ao fato de que os jovens percebem o silêncio dessas instituições, quando se tratando desse assunto, ainda que eles queiram esclarecimentos daqueles que os/as educam: pais e professores/as. Braga (2003) trouxe essa conclusão após ter realizado uma pesquisa com adolescentes, objetivando colher informações sobre o papel da escola frente à orientação sexual dos/as jovens.

Diante dos aspectos levantados até o momento, pode-se dizer que a internet e os outros meios da mídia, os/as colegas, a família, as palestras sobre prevenção de DST's, as aulas sobre a reprodução humana como forma de falar sobre sexualidade, podem influenciar negativamente nas concepções e valores da criança ou do/a adolescente, se forem transmitidas sem que haja uma devida reflexão crítica sobre o assunto e sem que haja uma abordagem que inclua todas as questões que dele fazem parte.

Para Ribeiro (1990), esses valores e informações são incorporados pelo indivíduo e aceitos como verdades que não são questionadas. Dessa forma, o conceito relacionado à sexualidade é aprendido de forma distorcida em razão da falta de um espaço que possibilite reflexões e debates entre ideias e concepções diferentes. O autor defendia, num momento anterior da oficialização do tema no currículo escolar, que a escola poderia se configurar como um dos espaços de orientação sexual, onde os 
pensamentos e questões não seriam proibidos e onde a formação do conceito sobre sexualidade aconteceria de maneira crítica e reflexiva.

Compreende-se, portanto, pela ideia trazida por Ribeiro (1990) a respeito desta forma crítica e reflexiva na qual ocorreria o referido processo de ensino e aprendizagem, que este aconteceria sem a imposição de conceitos feita por parte de professores/as, mas por meio da reflexão e discussão acerca de informações e conhecimentos trazidos para encontros entre educadores/as e alunos/as, se assim fossem abertos espaços na escola.

Sendo assim, percebe-se, pelas colocações dos/as autores/as mencionados até então, que, muito embora se reconheçam a necessidade da escola em falar sobre sexualidade com os/as educandos/as, são percebidas práticas aquém dos ideais proferidos pelos/as estudiosos/as, bem como pelas propostas das instâncias superiores de educação, em especial transmitidas por intermédio dos PCNs (BRASIL, 1998), no que tangem a esse assunto. Conforme Reis e Ribeiro (2005 p.31):

\footnotetext{
Nós, indivíduos do século XXI, ainda sofremos as consequências desta moral anti-sexual rígida, austera, contida, que influenciou profundamente as atitudes em relação à sexualidade. É neste quadro que inserimos a questão da orientação sexual na escola. Quando levamos para a escola a tentativa de trabalhar com a sexualidade, levamos junto com essas propostas e projetos toda esta história de repressão e preconceitos.
}

Nesse sentido, seria como dizer que se é pretendido falar sobre o tema em questão na escola, ter-se-ia que considerar as dificuldades que possivelmente seriam encontradas, ter-se-ia que considerar a história da sexualidade, a qual passou por um longo período de concepções repressoras e saber que as coisas, ou melhor, dizendo, as pessoas, não mudaram como era esperado.

Embora os estudos e as pesquisas tragam novas concepções, muitas vezes, não são suficientes para fazer com que as pessoas repensem seus conceitos e opiniões, superando o senso comum. Não, pelo menos, facilmente. Mas, qual seriam, afinal, as principais dificuldades da escola? Qual a razão que leva a escola a não por em prática as propostas apresentadas nos PCNs (BRASIL, 1998) acerca do tema?

Para responder a tais perguntas, torna-se necessário neste ponto a discussão sobre os fatores que influenciam na dificuldade da escola em promover a educação ou orientação sexual, conforme os/as pesquisadores/as.

Um dos entraves a respeito da implantação da Orientação Sexual citados por Santos e Bruns (2000) é relacionado à resistência por parte da família, dos/as 
funcionários/as e mesmo dos/as professores/as, para trabalhar-se com o tema. Resistência essa, segundo as autoras, fruto da repressão sexual. Assim:

O corpo docente das escolas, composto por pessoas que tiveram sua sexualidade permeada pela repressão sexual, enfrenta muitas dificuldades para lidar com a expressão da sexualidade nos domínios da escola, punindo, em grande parte das vezes, essas manifestações e, assim, contribuem para afastar o educando de uma vivência autêntica do diálogo. (SANTOS; BRUNS, 2000, p.90).

Em realidade, o que ocorre é a reprodução da educação recebida pelos membros da equipe escolar, que transmitem para as novas gerações de educandos/as uma educação baseada em valores morais próprios, relacionados a uma concepção de sexualidade desatualizada em relação às ideias trazidas pelos/as autores/as contemporâneos, bem como, pelos PCNs (BRASIL, 1998).

Além disso, a dificuldade de tratar sobre o tema poderia estar relacionada também, de acordo com Gagliotto e Lembeck (2011), ao fato de que o/a professor/a pode se sentir inseguro ao tratar do tema sexualidade devido ao receio das consequências de seu trabalho junto aos pais e à comunidade.

A dificuldade de se falar sobre o assunto, deriva de uma concepção repressora onde a sexualidade é um tabu, sendo difícil que os agentes escolares abordem o tema de forma diferente da que aprenderam, ou ainda, diferente da concepção aprendida pela comunidade e família dos/as educandos/as, os quais podem sentir-se invadidos, por razão da questão abarcar valores pessoais e, por esse motivo, poderiam ainda tentar impedir a escola de realizar projetos em que a temática fosse trabalhada.

Neste sentido, a formação do/a professor/a torna-se um ponto importante para ser considerado, de forma que propicie práticas escolares condizentes com o esperado pelas propostas educacionais e por pesquisas reconhecidas. Conforme Silva (2002, p.26): “[...] a formação do educador sexual é básica no sentido de preparar as pessoas em nível de conhecimento, metodologia e postura para trabalharem na escola com um tema que é ainda polêmico na nossa sociedade".

No entanto, Figueiró (2006) aponta a formação docente como um dos principais aspectos que dificultam o trabalho com a sexualidade no âmbito escolar. Para elucidar a questão, a autora faz referência a pesquisadores/as da área que demonstraram em suas pesquisas, as opiniões dos/as professores/as quanto à inserção do tema sexualidade no currículo escolar. Dessa forma explicita: “[...] o que se percebe de comum nos vários estudos supramencionados é o apontamento feito, pelos profissionais investigados, de 
que reconhecem a necessidade de uma preparação específica.” (FIGUEIRÓ, 2006, p.76).

Nesse sentido, fica claro que os/as professores/as ainda se sentem despreparados para concretizar ações a respeito da abordagem da sexualidade na escola, reconhecendo ser necessária uma formação que lhes possibilite o conhecimento suficiente para lidar com um assunto que ainda parece ser complexo para a sociedade. Isto também é evidente quando temos conhecimento sobre determinadas práticas que são observadas e sofrem críticas por pesquisadores/as, alguns citados até então.

Sendo assim, a formação inicial e continuada do profissional que lidaria com a educação ou orientação sexual (OS) na escola, demandaria o estudo de vários tópicos importantes que o circundam, tal como Silva (2002, p.108) explica:

\begin{abstract}
A dimensão da formação no trabalho de OS é complexa e multirreferencial, pois há que se envolver com a história e com as implicações socioculturais e políticas da sexualidade, com as questões de gênero, na construção do masculino e do feminino, com a compreensão do desenvolvimento da criança, do adolescente e do adulto, enquanto construção da base dos afetos e da rede dos relacionamentos e, por fim, compreendendo as muitas possibilidades de interligações entre sexualidade, prazer e aprendizagem.
\end{abstract}

Como pode-se observar, a formação do profissional é de suma importância para que as novas experiências em relação ao trabalho com a sexualidade na escola sejam eficientes, pois de nada adiantaria a oficialização do tema no currículo se não fossem dados os suportes necessários para que a equipe escolar colocasse em prática as propostas em relação à “Orientação Sexual” de maneira correta. Desse modo, é possível observar pela fala de Silva (2002), acima citada, que, se quisermos que os/as educandos/as compreendam a sexualidade em todas as suas dimensões, como também sobre todas as perspectivas influentes, temos que compreender também que, para isso, os próprios profissionais devem ser esclarecidos a respeito de todos esses conhecimentos pretendidos, por meio da formação inicial e/ou continuada.

Além disso, segundo Ribeiro (1990), para que o/a profissional esteja habilitado a trabalhar com a "orientação sexual" na escola, é preciso que tenha um total esclarecimento a respeito de sua própria sexualidade, a fim de que possa se sentir a vontade em falar sobre tal assunto. Deverá, também, ter conhecimento em relação aos aspectos teóricos da área, desenvolvendo um trabalho que considere em seu planejamento, as necessidades e expectativas dos/as educandos/as. 
Quanto à transversalidade proposta pelos PCNs (BRASIL, 1998), de acordo com Figueiró (2006), ainda se configura em um processo que será instaurado na escola de modo lento. Dessa forma, conforme a autora, seriam necessárias algumas ações para que a implantação da transversalidade fosse conseguida com êxito. Entre essas, o trabalho feito em equipe pelo conjunto de professores/as da escola, de acordo com ela, seria importante em se tratando de um tema que deve perpassar várias disciplinas, assim como também apontam Santos e Bruns (2000).

Entretanto, Figueiró (2006) cita algumas outras ações que, como essas, seriam muito importantes para a prática transdisciplinar na escola. Essas ações envolveriam a formação de professores/as, sobre a qual as Universidades deveriam ter responsabilidade, assim como sobre as pesquisas na área, e envolveria também, o apoio dado pelas instâncias superiores de educação para viabilizar as novas propostas para a escola. A autora faz referência a vários outros pesquisadores/as que revelam certa preocupação com a oficialização da educação sexual nas escolas, apontando falta de preparo dos/as professores/as para lidarem com o tema, como um problema a ser enfrentado.

Contudo, considerando sua oficialização no currículo escolar, não há mais como ignorar a necessidade de se trabalhar a sexualidade nesse contexto. Em outras palavras, se chegamos num ponto da história da sexualidade, no qual ela fora compreendida como sendo inerente à vida do ser humano e que, portanto, deve ser um tema a ser abordado pela instituição educacional, como reconhecidamente propõe o Ministério da Educação nos PCNs (BRASIL, 1998), bem como pesquisadores/as da área da educação ou afins, então é preciso que os/as educadores/as repensem sobre o assunto em questão e sobre os demais assuntos envolvidos, para que finalmente, seja encontrada uma maneira de todas as escolas colocarem em prática o que fora idealizado desde, pelo menos, a década de 1990. Segundo Gagliotto e Lembeck (2011, p.95):

\footnotetext{
Realizar orientação sexual na escola era proibido oficialmente. Atualmente o momento é outro. A escola não pode mais fugir ao seu papel de educadora e ignorar a questão sexual do aluno e tampouco acreditar que, dando apenas informações biológicas, como palestras uma vez ao ano, já está fazendo educação sexual [...].
}

Com isso, as autoras colocam para reflexão o fato de que é necessária a preocupação com a efetivação da "Orientação Sexual" nas escolas, mas que também, deve-se pensar em como essa está sendo realizada, na tentativa de atender às propostas 
dos PCNs (BRASIL, 1998), visto que, nem sempre, as práticas escolares estão em conformidade com aquilo que os/as pesquisadores/as e estudiosos/as pensam acerca da orientação ou educação sexual. Então, qual seria o caminho?

Conforme visto anteriormente e conforme as autoras acima citadas igualmente retrataram no trecho exposto, nos programas de orientação sexual geralmente o tema é trabalhado destacando-se informações sobre a biologia sexual, enquanto outras implicações sobre a sexualidade, referentes aos aspectos inerentes à condição humana e às relações interpessoais, tais como o desejo e a afetividade, os quais deveriam ser abordados pela escola são em realidade, ignorados (RIBEIRO, 1990).

Para tanto, seria necessário que a equipe escolar compreendesse a sexualidade de forma ampla, conforme assinalam Santos e Bruns (2000, p.13):

[...] é possível compreender a sexualidade por uma perspectiva mais abrangente, a qual possui uma conotação que envolve dimensões além dos limites biológicos, incluindo o relacionamento, o erotismo, a fantasia, o prazer e também as questões ligadas à cultura, à religião, à simbolização, aos interditos e à própria construção do ser humano, e não apenas a genitalidade.

A prevenção de doenças sexualmente transmissíveis, a gravidez indesejada, a biologia sexual, entre outros temas, seriam importantes de serem tratados. Entretanto, os/as educadores/as devem compreender que não adiantaria ignorar outros fatores positivos da sexualidade, tais como, o prazer e a afetividade, como se não falar a respeito, fosse inibir as manifestações, ações ou curiosidade das crianças e jovens sobre sua própria sexualidade e por consequência, fosse protegê-los/as das responsabilidades acarretadas, bem como dos riscos de uma vivência sexual sem os cuidados necessários.

Pelo contrário, como foi possível observar, esse silêncio da escola a respeito dos outros fatores envolvidos na sexualidade humana, acarreta a busca de informações por meio de fontes não confiáveis e que podem influenciar de maneira negativa sobre a postura do indivíduo, ao invés de ajudar nos esclarecimentos necessários para uma boa vivência em relação à sexualidade, e no tratamento desta de forma responsável. Simonetti (1994) citada por Figueiró (2006, p.58), aponta:

[...] é preciso fazer com que os educadores entendam que a principal razão para desenvolvê-la nas escolas é o direito que a criança e o adolescente têm de conhecer seu corpo e a sexualidade, com uma visão positiva dessas realidades, e a necessidade de rever e transformar as formas de relação afetivo-sexual entre duas pessoas, sejam elas de sexo diferente ou igual. 
Dessa forma, seria necessário que o conteúdo para a abordagem do tema nas escolas, não fosse meramente informativo ou determinador de padrões culturais. Ele deveria ser um conteúdo crítico que abarcasse questões que tivessem envolvimento com as relações humanas, promovendo atitudes responsáveis e o respeito ao outro (RIBEIRO, 1990).

Segundo Figueiró (2006) o educador sexual deve estar comprometido em fazer dois tipos de resgate. O primeiro é o "resgate de gênero", implicando na conscientização dos direitos iguais a homens e mulheres; o segundo seria o "resgate do erótico", o qual implica que o educando possa eliminar a visão de que a sexualidade é algo "feio", associada à luxúria.

Compreende-se que a autora trouxe essas duas dimensões para se trabalhar a sexualidade na escola, ao considerar os problemas identificados na sociedade acerca de sua compreensão e talvez, por isso, utilizou a palavra resgate ao falar sobre o gênero e o erótico, não mencionando a prevenção neste caso, pois esta, como pode-se perceber, já ocorre em algumas escolas de alguma forma, e além disso, já é enfatizada pelos PCNs (BRASIL, 1998).

Contudo, esse conteúdo, de acordo com Silva (2002), deveria responder às necessidades e interesses apresentados pelos/as alunos/as, e a esses, deveria ser garantida a participação no processo, planejamento e avaliação.

Assim, a participação do/a aluno/a no processo torna-se importante uma vez que se o objetivo do processo educativo é fazer com que o/a aluno/a aprenda, como não considerá-lo quando estamos planejando os conteúdos e metodologias das aulas?

Percebe-se que é proposta uma metodologia onde o/a aluno/a não é apenas um receptor de conteúdos impostos por outrem e sim, um membro importante no processo de ensino e aprendizagem em relação à sexualidade. Nesta perspectiva, atividades cujos conteúdos são apenas informativos e não garantem a participação nem o diálogo entre os/as educandos/as, seriam eliminadas dos componentes metodológicos de um projeto para o conhecimento sobre sexualidade humana, pois não dariam ao/à educando/a oportunidade de exporem suas reais curiosidades e interesses.

As palestras que comumente são utilizadas de maneira isolada nas escolas, ministradas por profissionais de outras áreas, não teriam grande serventia para o esclarecimento das crianças e jovens, como também para a mudança de posturas, se não estivessem inseridas em um contexto de um trabalho mais amplo sobre a sexualidade e 
assim, representassem um bom recurso dentro de um ensino sistematizado (SANTOS; BRUNS, 2000).

Quanto ao professor e à professora, como visto anteriormente, é preciso superar suas dificuldades pessoais em lidar com o assunto na escola, o que implicaria em aprofundados estudos acerca dos assuntos relacionados à sexualidade. Todavia, há que se considerarem algumas colocações quanto à postura que este/a profissional deveria assumir para a abordagem do tema com os educandos. Para Silva (2002), o principal papel do/a professor/a neste processo, é o de trazer questionamentos aos/às alunos/as e não o de expor suas experiências acerca do assunto discutido. Ou seja, é importante que o/a professor/a mantenha uma atitude profissional e ética no trabalho, estabelecendo uma distância entre as aulas e suas histórias pessoais.

Além disso, cada membro da equipe escolar carrega consigo suas próprias concepções e valores referentes às questões relacionadas à sexualidade, construídos em suas vivências e aprendidos por intermédio dos meios de comunicação, da família, da religião, entre outros meios. Muitas vezes, conforme já visto, são frutos de posturas repressoras que não consideram a sexualidade como sendo algo inerente à vida, tendendo-se a impor determinadas visões em detrimento de outras, como sendo a verdade absoluta. Nesse caso é importante lembrar que:

\footnotetext{
Os valores de cada um devem ser respeitados. Discutir aspectos da sexualidade não significa a determinação ou a imposição de uma única e específica forma de encarar a questão. Ao nível de valor, não existe o certo e o errado, o verdadeiro e o falso e, neste sentido, o confronto e a discussão de opiniões são fundamentais para que o próprio aluno tenha condições de se posicionar. (GAGLIOTTO; LEMBECK, 2011, p.106).
}

Assim, não se trata de transmitir apenas uma visão sobre sexualidade, como se existisse uma definição única para cada uma das questões relacionadas, visto que existem valores envolvidos na concepção sobre o tema, e sabe-se que, em relação aos valores, cada pessoa tem os seus. O interessante no caso, seria o conhecimento sobre os mais diversos pontos de vista por meio do confronte de ideias e de visões distintas, a fim de que o educando pudesse ter suas opções acerca dos aspectos referentes ao tema, fundamentadas em reflexões realizadas de maneira consciente, ao invés de aceitar uma determinada ideia imposta por ignorância por parte de educadores/as. 
Considerando um dos entraves apresentados em relação à abordagem da sexualidade no âmbito escolar como sendo a resistência por parte da família, torna-se essencial trazer as ideias e propostas dos/as autores/as quanto a essa situação.

A respeito disso Gagliotto e Lembeck (2011, p.106) assinalam: “[...] a escola não pode significar a substituição do papel da família na educação sexual da criança e/ou adolescente, mas, sim, é corresponsável”. Isso significa dizer que a escola deveria fazer um trabalho em conjunto com a família no que se refere à sexualidade, pois ambas têm sua responsabilidade sobre essa questão, como também é reconhecido nos PCNs (BRASIL, 1998).

Em suma, compreende-se que a sexualidade é definida pela sociedade de acordo com concepções repressoras, como também, por concepções liberais, segundo a definição de Ribeiro (1990), com base em estudos realizados na década de 1990, mas que, conforme foi percebido e explicitado no decorrer deste capítulo pode ser uma constatação pertinente ainda em tempos atuais.

$\mathrm{Na}$ escola, isso não é diferente. Observa-se que algumas das dificuldades apresentadas decorrem justamente dessa divergência entre as concepções existentes, sem considerarmos uma das questões primordiais acerca do tema, que refere-se à formação do/a professor/a.

Contudo, pesquisadores/as, estudiosos/as e instâncias superiores relacionadas à educação, reconhecem a importância de o tema sexualidade ser abordado dentro da instituição escolar e, mediante a sua oficialização no currículo, por meio dos PCNs (BRASIL, 1998), torna-se necessária a modificação no campo educacional a fim de atender às propostas, considerando-se que o assunto envolve uma questão de direitos humanos e considerando-se ainda, a importância deste tema para uma educação brasileira comprometida com a formação do indivíduo de forma integral e com a transformação social. Assim, de acordo com Gagliotto e Lembeck (2011, p.108):

É urgente e necessária a construção de projetos de educação sexual na escola, assim como alimentar a esperança política de transformações nas bases de nossa sociedade capitalista, que poderá se efetivar através dos espaços institucionais e pedagógicos. A expectativa é a de que essa intervenção não caia em ações pontuais, mas que um dia possa ser implementada de maneira efetiva em todo o sistema educacional.

Reconhece-se, portanto, a importância de medidas que são realizadas com o objetivo de trazer o tema sexualidade na escola para debate. Assim sendo, não pretendeu-se com o presente artigo, esgotar os assuntos referentes ao tema em questão, 
mas sim, não deixá-lo esquecido frente a tudo que foi exposto até o momento, sendo necessário o aprofundamento em determinadas questões, a fim de que seja possível uma proximidade cada vez maior entre as pesquisas, as propostas advindas de políticas públicas e a realidade da escola brasileira.

\section{SEXUALITY AND EDUCATION: AN ESSENTIAL DEBATE}

ABSTRACT: This paper comprises an examination on sexuality, as well as how it is comprehended by educators. Thus, we intend to clarify and discuss some conceptions and concepts disseminated throughout History about the human sexuality, as well as concerned to the institutionalization of education of the abovementioned issue. This became an educational policy, in Brazil, through the Parâmetros Curriculares Nacionais - PCNs (National Curriculum Parameters) (BRASIL, 1998). To do so, we unveiled concepts and ideas from various authors who studied it in order to offer readers a reflection over the experienced obstacles when dealing with such a polemic subject in the classrooms. Based on the self-evident truth that sexuality is inherent to life and taking into account the perceptions of an individual about it during his/her lifetime, it is extremely crucial to analyze how such matter is approached in an educational environment. Hence, we expect that this article may contribute to several other scholarly papers and researches about the aforementioned topic

KEYWORDS: School. Sexuality. Sexual education. Sexual orientation. National Curriculum Parameters.

\section{REFERÊNCIAS}

AQUINO, J. G. (Org.). Sexualidade na escola: alternativas teóricas e práticas. São Paulo: Summus, 1997.

BRAGA, M. R. Adolescência e educação sexual: desafio para o novo século. In: BRAGA, M. R. Um olhar da psicologia sobre a educação: diagnóstico e intervenção na infância e na adolescência. São Paulo: Arte \& Ciência, 2003. p.147-165.

BRASIL. Ministério da Educação. Secretaria de educação fundamental. Parâmetros Curriculares Nacionais: terceiro e quarto ciclos do ensino fundamental: temas transversais - orientação sexual. Brasília: MEC, 1998.

FIGUEIRÓ, M. N. D. Formação de educadores sexuais: adiar não é mais possível. Campinas: Mercado de Letras; Londrina: Eduel, 2006. (Dimensões da Sexualidade).

GAGLIOTTO, G. M.; LEMBECK, T. Sexualidade e adolescência: a educação sexual numa perspectiva emancipatória. Educere et Educare: Revista de Educação, Cascavel, v.6. n.11, p.93-109, jan./jun. 2011. 
GUIMARÃES, I. Educação sexual na escola: mito e realidade. Campinas: Mercado de Letras, 1995.

KAHHALE, E. M. S. P. Subsídios para reflexão sobre sexualidade na adolescência. In: BOCK, A. M. B.; GONÇALVES, M. G. M.; FURTADO, O. (Org.). Psicologia sóciohistórica: uma perspectiva crítica em psicologia. 5.ed. São Paulo: Cortez, 2011. p.179191.

REIS, G. V.; RIBEIRO, P. R. M. Sexualidade e educação escolar: algumas reflexões sobre orientação sexual na escola. In: BORTOLOZZI, A. C.; MAIA, A. F. Sexualidade e Infância. Bauru: FC/CECEMCA; Brasília: MEC/SEF, 2005. p.34-45.

RIBEIRO, P. R. M. A sexualidade na história. In: RIBEIRO, P. R. M. (Org.). Sexualidade e educação sexual: apontamentos para uma reflexão. São Paulo: Cultura Acadêmica Editora, 2002. p.9-16.

Educação sexual além da informação. São Paulo: EPU, 1990.

Sexualidade também tem história: comportamentos e atitudes sexuais através dos tempos In: BORTOLOZZI, A. C.; MAIA, A. F. Sexualidade e infância. Bauru: FC/CECEMCA; Brasília: MEC/SEF, 2005. p.16-33.

SANTOS, C.; BRUNS, M. A. T. A educação sexual pede espaço: novos horizontes para a práxis pedagógica. São Paulo: Ômega, 2000.

SAYÃO, Y. Orientação sexual na escola: os territórios possíveis e necessários. In: AQUINO, J. G. (Org.). Sexualidade na escola: alternativas teóricas e práticas. São Paulo: Summus, 1997. p.107-117.

SELIGMAN, F. CNJ obriga cartórios de todo o país a celebrar casamento entre gays. Folha de São Paulo, São Paulo, 14 mai. 2013. Disponível em:

$<$ http://www1.folha.uol.com.br/cotidiano/2013/05/1278302-cnj-estabelece-casamentogay-em-todo-pais.shtml>. Acesso em: 21 mai. 2013.

SILVA, R. C. Orientação sexual: possibilidade de mudança na escola. Campinas: Mercado de Letras, 2002. (Dimensões da Sexualidade).

SIMONETTI, C. Sexualidade na adolescência e programas de educação sexual. Boletim Transa Legal para educadores, São Paulo, v.1, n.1, p.2, mai./jun. 1994.

SOUZA, M. C. C. C. Sexo é uma coisa natural? a contribuição da psicanálise para o debate sexualidade/escola. In: AQUINO, J. G. (Org.). Sexualidade na escola: alternativas teóricas e práticas. São Paulo: Summus, 1997. p.11-25.

WEREBE, M. J. G. Sexualidade, política e educação. Campinas: Autores Associados, 1998.

WYLlYS, J. Homossexualidade: Encontro com Fátima Bernardes. [mar. 2013]. Entrevistador: Fátima Bernardes. Rio de Janeiro: TV Globo, 2013. 